\title{
Commercial gillnetting is more stressful for saithe (Pollachius virens L.) than jigging: but is fillet quality affected?
}

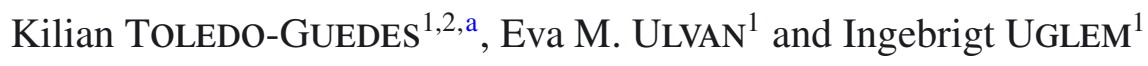 \\ 1 Norwegian Institute of Nature Research, PO Box 5685 Sluppen, 7485 Trondheim, Norway \\ 2 Dept. of Marine Sciences and Applied Biology, University of Alicante, PO Box 99, 03080 Alicante, Spain
}

Received 16 September 2015; Accepted 2 April 2016

\begin{abstract}
Various fish capture methods, which involve different levels of pre-slaughter stress/welfare, could influence the final quality of marketed fish. In this study, living saithe (Pollachius virens L.), caught during realistic commercial fishing by gillnetting $(n=37)$ and automatic jigging $(n=50)$, were analysed for stress indicators in blood parameters. An assessment of the fillet quality of the same fish, after four days storage on ice, was carried out using an Industrial Test (IT) and a Quality Index Method (QIM). Stress indicators in gillnetted fish, such as lactate $(7.5 \pm 0.6 \mathrm{mmol} / \mathrm{L})$, haematocrit $(33.9 \pm 1.2 \%)$ and glucose $(6.7 \pm 0.7 \mathrm{mmol} / \mathrm{L})$ were significantly higher when compared to jigged fish $(2.6 \pm 0.2 \mathrm{mmol} / \mathrm{L}, 23.7 \pm 0.7 \%$ and $3.3 \pm 0.1 \mathrm{mmol} / \mathrm{L}$, respectively), indicating higher stress levels for fish caught with gillnets. No differences due to fishing gear were detected in the quality indexes, which seemed to be influenced by a potential bias introduced when only fish hauled on board alive were analysed, and the limitations of the QIM and IT to detect small differences in quality. Condition factor $(K)$ was positively correlated with IT for gillnetted fish, but not for jigged fish. This could also mask potential effects of capture methods on fillet quality. These results will be valuable given emerging concerns on fish welfare in commercial fisheries and the need to deliver fish products with high quality standards.
\end{abstract}

Keywords: Saithe / blood parameters / stress / welfare / quality indexes / catching method

\section{Introduction}

There is growing consumer concern regarding quality (sensu lato) of food of animal origin (Nielsen et al. 2002). Raw fish is a highly perishable product and its quality is strongly dependent on various factors throughout the production chain (Poli, 2009). One of these factors is pre-slaughter stress, which may also influence fish welfare. Producers and suppliers therefore focus on developing handling procedures that may improve quality, and in turn increase the value of their products (Hughes 1995). Nonetheless, stress/welfare and its relation to final quality in wild-capture fisheries is an issue scarcely, and only recently, studied (Metcalfe 2009; Diggles et al. 2011).

It is commonly accepted that there is a relationship between fishing technique and final fillet quality. Previous studies indicate that fillet quality is better in fish captured by hook (e.g. longline, jigging) than in fish captured by more invasive techniques, such as trawling or gillnetting (Botta et al. 1987; Santos et al. 2002; Özyurt et al. 2007; Rotabakk et al. 2011). This is attributed to differences in stress levels, net soaking time, on-board handling, and the mechanical pressure exerted on the fish. However, fish quality is also influenced by factors other than fishing technique, such as storage conditions, time

a Corresponding author: ktoledo@ua.es of year, somatic conditions, or the species' sensitivity to stress. The latter has led to contradictory results depending on the quality indexes and species selected for each study (Esaiassen et al. 2004).

There are different physiological responses related to stress during capture and slaughter, linking capture methods to final quality of the fish product. The ability of different species to maintain aerobic metabolism during harvest will drive their acid-base and electrolyte balance (Wilkinson et al. 2008), thus influencing blood parameters (e.g. blood gases, glucose, lactate), which can be used as stress indicators. Stress both before and during slaughter can reduce $\mathrm{pH}$ in the muscle (Roth and Rottabak 2012) and increase the incidence of rigor mortis, which in turn may reduce final fillet quality (Poli et al. 2005).

Norway has the largest saithe (Pollachius virens L.) fishery in the world, with $90 \%$ of total catches worldwide. Over the last 51 years, the average annual catch has been 163000 tons, making saithe the second most captured demersal fish in Norway, only surpassed by Atlantic cod (Gadus morhua). The Norwegian saithe catch originates from bottom trawl (40\%), purse seine $(25 \%)$, gillnet $(20 \%)$ and from other conventional gears (15\%), including long line, Danish seine and hand line (Norwegian Directorate of Fisheries 2013). Given the diversity in capture methods, a better understanding of how the different 
Table 1. Summary of the meristic variables of the sampled fish. $* *=$ significant differences $(p<0.01)$ between jigging and gillnet groups. HSI is the Hepatosomatic Index) and $K$ is the somatic condition factor.

\begin{tabular}{cccccc}
\hline Fishing gear & $n$ & $T L(\mathrm{~cm})$ & Weight $(\mathrm{kg})$ & HSI $(\%)^{* *}$ & $K^{* *}$ \\
\hline Jigging & 50 & $66 \pm 7$ & $2.84 \pm 0.96$ & $6.18 \pm 3.1$ & $0.94 \pm 0.14$ \\
Gillnetting & 37 & $66 \pm 6$ & $2.94 \pm 0.74$ & $8.59 \pm 3.78$ & $1.03 \pm 0.15$ \\
\hline
\end{tabular}

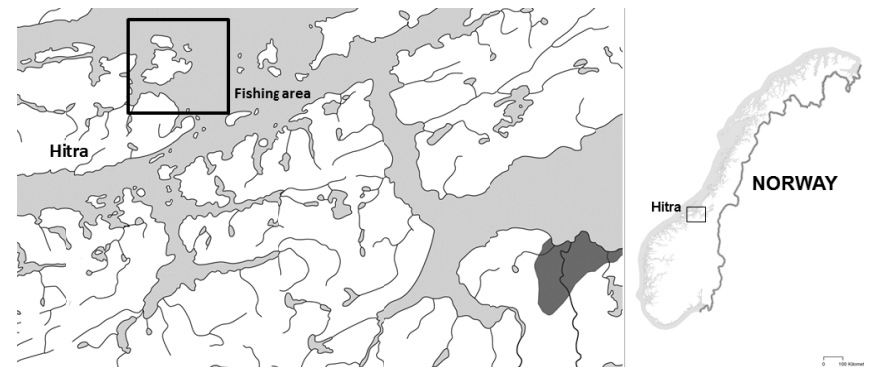

Fig. 1. Map of the study area and sampling locations.

fishing techniques affect the physiological status of the fish during capture (e.g. stress response) and in turn flesh quality, would be important for improving final product quality.

The aim of this study was to investigate whether two different fishing methods currently used in the commercial saithe fishery in Norway result in differences in post-capture stress parameters, and if different, whether these differences could be correlated with measureable differences in final product quality (fillet quality). Blood parameters indicative of physiological stress were measured for saithe caught by gillnetting and jigging. Finally, fish quality, which can be measured in several ways, was assessed as organoleptic characteristics (odour, colour and texture of the fillet; Olafsdóttir et al. 1997) graded through a Quality Index Method scheme (QIM; Martinsdóttir et al. 2003).

\section{Materials and methods}

\subsection{Study area and fishing techniques}

Between November 2014 and April 2015, a total of 212 saithe were caught (average weight \pm standard deviation $=2.85 \mathrm{~kg} \pm 0.83 \mathrm{~kg}$ ) on the north-eastern side of the Island of Hitra (N63.62, E08.99) in Norway (Fig. 1). The saithe were collected using both gillnets which were soaked between 15 and $17 \mathrm{~h}(n=121)$, and jigging machines (Belitronic BJ5000) that hauled the fish on board in $2-3 \min (n=91)$.

\subsection{Sampling procedure}

Immediately following retrieval, the conscious state of the fish was quickly evaluated using the parameters defined by Kestin et al. (2002), based on physical responses to handling and opercular movement. Using these parameters, fish were classified as dead or alive (conscious) and mortality rates for each fishing gear calculated. A representative number of live fish caught by both fishing methods were blood sampled (see Sect. 2.3 below) and then killed by a blow to the head.
Then, total length $( \pm 1 \mathrm{~cm})$ and weight $( \pm 10 \mathrm{~g})$ were recorded before the fish was bled out in a tank containing seawater at ambient temperature. Thereafter, each fish was eviscerated and its liver weighed $( \pm 1 \mathrm{~g})$. These data were used to calculate the Hepatosomatic Index - HSI $=($ liver weight $/$ fish weight $) \times 100$ - and condition factor $-K=\left(\right.$ fish weight/fish length $\left.{ }^{3}\right) \times 100$ - see Table 1 for a summary of morphometric measurements.

\subsection{Blood sampling and analysis}

A subset of 87 blood samples was collected from fish that were alive when hauled on board (jigging $n=50$, gillnetting $n=37$ ). The blood was drawn from the caudal vessels of the fish with heparized syringes and analysed using an epoc ${ }^{\circledR}$ Reader and Host ${ }^{2}$ Mobile Computer together with epoc ${ }^{\circledR}$ BGEM Test Cards (Epocal Inc., Ottawa, Canada) within five minutes after extraction. Blood was automatically heated to $37{ }^{\circ} \mathrm{C}$ and analysed for $\mathrm{pH}$, sodium $\left(\mathrm{Na}^{+}\right)$, potassium $\left(\mathrm{K}^{+}\right)$, calcium $\left(\mathrm{Ca}^{2+}\right)$, haematocrit $(\mathrm{Hct})$, glucose $(\mathrm{Glu})$, lactate (Lac), partial pressures of blood gases of carbon dioxide $\left(p \mathrm{CO}_{2}\right)$, oxygen $\left(p \mathrm{O}_{2}\right)$ and bicarbonate $\left(\mathrm{HCO}^{-}\right)$. Data on blood gases were discarded for those samples where bubbles were noted in the syringe. Partial gas pressures $p \mathrm{O}_{2}, p \mathrm{CO}_{2}$ and $\mathrm{pH}$ were adjusted to ambient seawater temperature $(T=7-$ $11^{\circ} \mathrm{C}$ ) according to Ashwood et al. (1983) and Mandelman and Skomal (2009) with the following formulas:

$$
\begin{aligned}
p \mathrm{O}_{2 \text { corr }} & =p \mathrm{O}_{2} \times 10^{-0.0058 \times \Delta T} \\
p \mathrm{CO}_{2 \text { corr }} & =p \mathrm{CO}_{2} \times 10^{-0.019 \times \Delta T} \\
p \mathrm{H}_{\text {corr }} & =p \mathrm{H}-0.015(T-37)
\end{aligned}
$$

where $\Delta T=37{ }^{\circ} \mathrm{C}-T$. Bicarbonate was calculated using $p \mathrm{H}_{\text {corr }}$ and $p \mathrm{CO}_{2 \text { corr }}$ through the Henderson-Hasselbalch equation:

$$
\mathrm{HCO}^{-}=\alpha \mathrm{CO}_{2} \times p \mathrm{CO}_{2 \text { corr }} \times 10^{(p \mathrm{Hcorr}-p \mathrm{Ka})}
$$

where $\alpha \mathrm{CO}_{2}\left(\mathrm{mmol} \mathrm{L}^{-1} \mathrm{mmHg}\right)$ was calculated using temperature corrected $\mathrm{pH}$ for each fish using Heisler's equation (Heisler 1984)

$$
\begin{aligned}
\alpha \mathrm{CO}_{2}= & 1.0064 \times 10^{-1}-5.4431 \times 10^{-3}(T) \\
& +2.1776 \times 10^{-4}\left(T^{2}\right)-4.9731 \times 10^{-6}\left(T^{3}\right) \\
& +4.5288 \times 10^{-8}\left(T^{4}\right) .
\end{aligned}
$$

Temperature specific $\mathrm{pK}_{\mathrm{a}}$ was calculated following an equation tested for salmonids (Boutilier et al. 1984) as specific constants for gadoids are unknown (Roth and Rotabakk 2012)

$$
\begin{aligned}
\mathrm{pK}_{\mathrm{a}}= & 6.4755 \times T^{-0.0187}+\log T\left(1.1704-0.1672 \mathrm{pH}_{\text {corr }}\right) \\
& +0.1073 \times \mathrm{pH}_{\text {corr }}-0.7511 .
\end{aligned}
$$


Table 2. Individual quality parameters and their ranges for each quality index used. QIM: Quality Index Method; IT: Industrial Test.

\begin{tabular}{|c|c|c|}
\hline Quality index & Parameter & Description \\
\hline \multirow{17}{*}{ QIM } & \multirow{5}{*}{ Smell } & 0 Fresh Sea \\
\hline & & 1 Neutral \\
\hline & & 2 Fishy \\
\hline & & 3 Ammonia \\
\hline & & 0 No splitting \\
\hline & \multirow{3}{*}{ Splitting } & 1 Initial splitting \\
\hline & & 2 Some loose fillet \\
\hline & & 3 Major disjoint fillet \\
\hline & \multirow{2}{*}{ Colour } & 0 Normal, fresh colour \\
\hline & & 1 Abnormal colour \\
\hline & & 0 Firm, natural \\
\hline & \multirow{3}{*}{ Consistence } & 1 Marginally soft \\
\hline & & 2 Soft \\
\hline & & 3 Very soft \\
\hline & \multirow{3}{*}{ Surface } & 0 Dry and shiny \\
\hline & & 1 Partly dissolved \\
\hline & & 3 Very dissolved \\
\hline \multirow{9}{*}{ IT } & \multirow{3}{*}{ Bend } & 0 Bends back fast \\
\hline & & 1 Bends back slow \\
\hline & & 2 Does not bend back \\
\hline & \multirow{4}{*}{ Pressure } & 0 Firm \\
\hline & & 1 Slightly soft, small mark \\
\hline & & 2 Very soft, deep mark \\
\hline & & 0 No splitting \\
\hline & \multirow[t]{2}{*}{ Splitting } & $\ldots$ \\
\hline & & 5 Major splitting \\
\hline
\end{tabular}

\subsection{Fillet quality analyses}

The eviscerated fish $(n=87)$ were stored in Styrofoam boxes with ice $\left(2-4{ }^{\circ} \mathrm{C}\right)$ for $96 \mathrm{~h}$, before the quality analyses were carried out. Excess water was removed and additional ice was added once during the storage period. As the purpose of this study was to detect potential differences between two groups and not to analyse fillet degradation over time or shelf life, the quality assessment was carried out four days after capture, i.e. after a sufficient period for avoiding confounding effects due to onset of rigor mortis. After storage, the saithe were filleted and the fillet quality assessed using a modified Quality Index Method (QIM) and a simple Industry Test (IT). Quality index methods have been developed and used for evaluating the quality of a range of fish species (Bonilla et al. 2007 and references therein) and are recognised as reference methods in sensory research (Olafsdóttir et al. 1997; Martinsdóttir et al. 2003). In this study, our rationale for using a QIM approach was the need for a fast, reliable and simple method for assessing quality that would also detect potential issues as experienced in fish landing facilities and by wholesalers.

The QIM test (Table 2) was based on a method developed for assessment of quality of Atlantic cod fillets (Akse et al. 2007), while the IT (Table 2) was based on a simpler test designed for rapid detection of significant texture-related quality defects for salmon (Salmo salar L.) fillets (Erikson et al. 2009). Both methods were slightly modified after preobservations of saithe captured in a pilot study in 2012 as they were originally developed for other species. In the QIM test, five fillet attributes (odour, splitting, colour, texture, and surface) were assessed and the maximum sum was 12 , while in the Industry Test three attributes (inelasticity, softness, and splitting) were assessed with a maximum sum of nine. The total score from both tests indicates decreasing fillet quality with increasing value. Three trained assessors carried out the quality evaluation, and the arithmetic mean of three independent assessments was used in the subsequent analyses.

\subsection{Statistical analyses}

One-way permutational univariate ANOVAs were carried out to explore meristic differences between gillnetted and jigged fish (i.e. total length, weight, Hepatosomatic Index and condition factor). In order to assess whether groups of samples could be separated, and which variables contributed most to the observed groups, a Principal Component Analysis (PCA) was performed on normalised blood parameters to avoid the potential influence of different scales. One-way permutational multivariate ANOVA (Anderson 2001) carried out over the Euclidean distances matrix allowed the detection of statistically significant differences between gillnetted and jigged fish. The design included one fixed factor "fishing gear" with two levels (jigging and gillnetting). Additionally, using the same design, permutational univariate ANOVA was performed for each blood parameter separately, for the fillet quality indexes, and their individual parameters. Finally, in order to assess the potential influence of $K$ on quality, an effect already described for cod (Gadus morhua L.) (Esaiassen et al. 2004), a linear regression with $K$ as a predictor of quality was used. The software PRIMER6 \& PERMANOVA + statistical package (Clarke and Gorley 2006) was used for the statistical analyses.

\section{Results}

All fish (100\%) captured by jigging were hauled on board alive, while mortality in gillnet captured fish was $27.3 \%$. Condition factor (K) and Hepatosomatic Index (HSI) were higher in fish captured with gillnets compared to jigged fish (Table 1). The two fishing methods were clearly separated in the PCA, although a third axis was needed to explain an adequate total amount of variability (64.4\%) and to identify which variables contributed to the separation (Figs. 2a and 2b). The groups were clearly separated by the first principal component (PC1) axis (35.4\% of variability) and the variables closely related to this axis were haematocrit (Htc: $r=-0.88$ ) and lactate (Lac: $r=-0.83$ ). The second principal component (PC2; $16.7 \%$ of variability) displayed intragroup variability due to differences in $\mathrm{pH}(r=0.73)$ and potassium $\left(\mathrm{K}^{+}: r=-0.76\right)$. The third axis (PC3; $12.3 \%$ of variability) was partially related to glucose (Glu: $r=-0.56)$ and calcium $\left(\mathrm{Ca}^{2+}: r=-0.49\right)$, even though marginally, these variables also contributed to intergroup separation.

Taking into account all the blood parameters, permutational ANOVA detected significant differences between fish captured with jigging and gillnets (pseudo- $F=18.333$; $p<$ 0.001 ), in concurrence with the results from the PCA. When 
Table 3. Mean values $( \pm$ SE) of blood parameters and quality indexes. Values in parentheses in the fishing gear columns indicate sample sizes for blood gases. Results of the permutational univariate ANOVA for each parameter and quality indexes $(\mathrm{n} . \mathrm{s}=$ non-significant, $* p<0.05$, $* * p<0.01, * * * p<0.001)$.

\begin{tabular}{cccccc}
\hline & \multicolumn{3}{c}{ Jigging } & \multicolumn{2}{c}{ Gillnet } \\
& $n=50(47)$ & $n=37(35)$ & \\
\hline & Mean \pm & $\mathrm{SE}$ & Mean \pm & $\mathrm{SE}$ & $p$-value \\
\cline { 2 - 6 }$p \mathrm{H}$ & 7.47 & 0.15 & 7.48 & 0.02 & n.s. \\
$p \mathrm{CO}_{2}(\mathrm{mmHg})$ & 6.9 & 0.3 & 7.5 & 0.3 & n.s. \\
$p \mathrm{O}_{2}(\mathrm{mmHg})$ & 59.6 & 5.5 & 44.1 & 5.2 & $*$ \\
$\mathrm{HCO}_{3}(\mathrm{mmol} / \mathrm{L})$ & 6.5 & 0.2 & 7.6 & 0.3 & $* *$ \\
$\mathrm{Na}^{+}(\mathrm{mmol} / \mathrm{L})$ & 174 & 3 & 179 & 1 & $* * *$ \\
$\mathrm{~K}^{+}(\mathrm{mmol} / \mathrm{L})$ & 4 & 0.2 & 3.4 & 0.2 & $*$ \\
$\mathrm{Ca}^{2+}(\mathrm{mmol} / \mathrm{L})$ & 1.35 & 0.05 & 1.53 & 0.05 & $* *$ \\
$\mathrm{Hct}(\%)$ & 23.7 & 0.7 & 33.9 & 1.2 & $* * *$ \\
$\mathrm{Hb}(\mathrm{g} / \mathrm{dL})$ & 8.1 & 0.2 & 11.5 & 0.4 & $* * *$ \\
$\mathrm{Glu}(\mathrm{mmol} / \mathrm{L})$ & 3.3 & 0.1 & 6.7 & 0.7 & $* * *$ \\
Lac $(\mathrm{mmol} / \mathrm{L})$ & 2.6 & 0.2 & 7.5 & 0.6 & $* * *$ \\
Quality Index Method $(\mathrm{QIM})$ & 2.6 & 0.2 & 2.4 & 0.1 & n.s. \\
Industrial Test $(I T)$ & 2.3 & 0.3 & 1.7 & 0.2 & n.s. \\
\hline
\end{tabular}

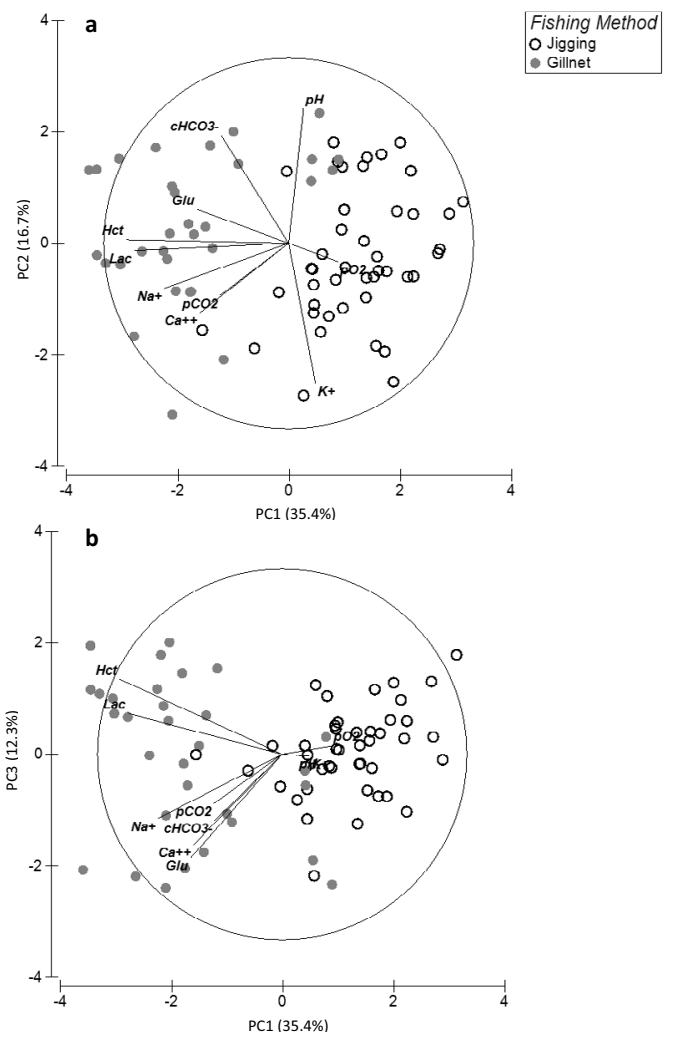

Fig. 2. Principal Component Analysis (PCA) showing ordination of fish samples in relation to blood parameters. (a) PC1 and PC2, (b) $\mathrm{PC} 1$ and PC3. Grey circles = gillnet, white circles = jigging.

considering each parameter separately, univariate permutational ANOVA detected intergroup differences in $\mathrm{pO}_{2}(p<$ $0.05), \mathrm{HCO}_{3}(p<0.01)$, sodium $(p<0.001)$, potassium $(p<0.05)$, calcium $(p<0.01)$, haematocrit $(p<0.001)$, glucose $(p<0.01)$ and lactate $(p<0.001$; Table 3$)$. Apart from $p \mathrm{O}_{2}$ and potassium that showed higher values in jigged fish, the blood parameter values were always higher in fish captured by gillnets (Table 3 ).

No differences were detected in QIM, IT, nor in the individual quality parameters, between the two fishing methods (Table 2). The regression models showed that IT was positively related to condition factor and explained $43.3 \%$ of the variability in quality, but only for gillnetted fish. The analysis did not find significant models for QIM and jigged fish assessed with IT (Fig. 3).

\section{Discussion}

Saithe captured in gillnets showed significantly stronger secondary stress responses, in terms of high levels of blood glucose, lactate, Hct and $\mathrm{Na}^{+}$, compared with fish caught by jigging. This suggests that jigging is better in terms of fish welfare than gillnetting, which is reasonable to expect as gillnetted fish may struggle for up to $17 \mathrm{~h}$ in the nets before being hauled on board, while fish caught with automatic jigging are killed within minutes after being hooked. Our results concur with those of Roth and Rottabak (2012) which showed similar differences between groups with different levels of capture-related exhaustion (comparable to our "jigging" and "gillnet" groups). Studies carried out in other species (e.g. bonefish Albula vulpes L., and different shark species) have also reported similar results (Manire et al. 2001; Cooke et al. 2008; Mandelman and Skomal 2009). The variable and unknown time fish spent in the gillnet could explain the variability found in blood parameters, which in general was larger for the gillnet group than the jigging group, as indicated by larger standard deviations in the former group.

The acid-base balance in marine fish is mainly regulated through the gills (Perry and Gilmour 2006). During exercise, excess $\mathrm{CO}_{2}$ in the blood promotes higher cardiac output and subsequent hyperventilation, which generates $\mathrm{HCO}_{3}^{-}$and $\mathrm{H}^{+}$ efflux and $\mathrm{Na}^{+}$and $\mathrm{Cl}^{-}$influx at the gill level. Compensation for systemic acidosis is achieved by increasing branchial net acid excretion, through increased $\mathrm{H}^{+}$excretion (coupled with 

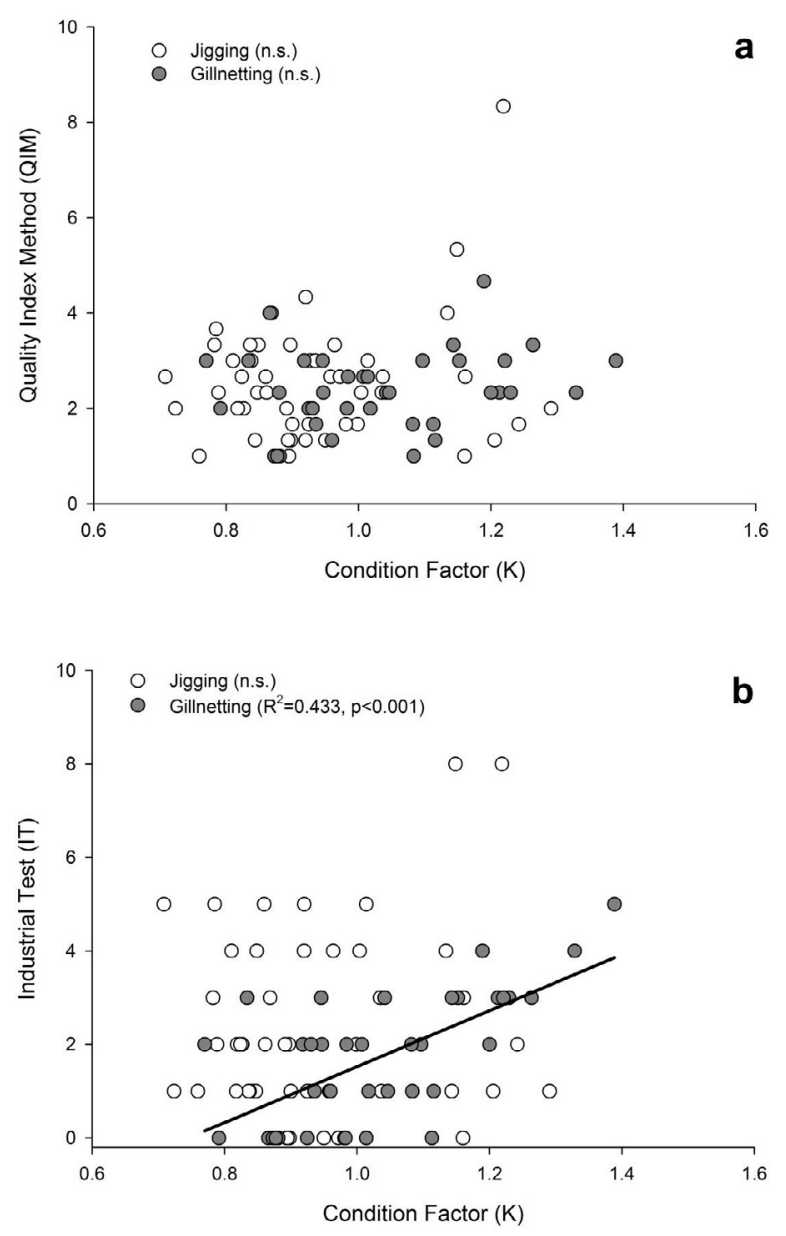

Fig. 3. Scatter plot showing condition factor $(K)$ versus (a) Quality Index Method and (b) Industrial Test for gillnetted (grey circles) and jigged (white circles) saithe. Only significant regressions are shown.

$\mathrm{Na}^{+}$intake) and/or decreased $\mathrm{HCO}_{3}^{-}$excretion, so as to accumulate $\mathrm{HCO}^{-}$and $\mathrm{Na}^{+}$ions (Gilmour and Perry 2009). In our study, no differences were detected in blood $\mathrm{pH}$ between the two fishing methods. This together with higher plasma concentrations of $\mathrm{HCO}_{3}^{-}$and $\mathrm{Na}^{+}$in gillnetted fish, suggest some degree of $\mathrm{pH}$ compensation response. This was also found by Roth and Rottabak (2012), when they compared nonexhausted and exhausted saithe. They also point out that blood $\mathrm{pH}$ was higher in longlined fish (i.e. fish caught on hooks and soaked from 6 to $12 \mathrm{~h}$ ), perhaps as a result of effective recovery in blood $\mathrm{pH}$. These seemingly contradicting observations could be related to the fishing gear used; while hooks may allow the fish to hyperventilate, gillnets may obstruct respiration (Chopin et al. 1996; Manire et al. 2001), thus impeding proper acid-base balance restoration.

Blood lactate has frequently been used as a stress indicator in fish (Wells and Pankhurst 1999; Brown et al. 2008; Currey et al. 2013). Lactate production occurs as a response to anaerobic metabolism, either due to hypoxia (including air exposure) or strenuous exercise (Kieffer 2000; Cooke et al. 2008), and may thus be considered as a stress response. The finding that the lactate levels were higher in gillnetted fish compared to fish caught by jigging suggests that gillnetting is more stressful for the fish than jigging and agrees with a recent study on secondary metabolites in saithe muscle (Maruhenda et al. 2015). It has also been found that muscle $\mathrm{pH}$ is negatively related to lactate levels in the blood (Roth and Rottabak 2012), even though only $20 \%$ of the lactate produced in the muscles is released into the blood (Wood 1991). In the current study, $\mathrm{pH}$ was not measured in muscle, but the lack of difference in $\mathrm{pH}$ in the blood does not exclude the possibility that $\mathrm{pH}$ in the muscle differed between the two capture techniques.

Pre-mortem stress is in general assumed to be determinative for fillet quality (Poli 2009; Lerfall et al. 2015). However, our results did not indicate any differences in fillet quality related to the fishing gear, although the stress levels were clearly different. Overall, the quality of the fish was good. Several factors could prevent the detection of fillet quality differences between jigged and gillnetted fish. One reason could be that all the fish analysed were alive when hauled on-board. This may partially mask differences in fillet quality as living fish were likely captured a short time before hauling. In total, $27.3 \%$ of the gillnetted saithe were hauled on board dead, and with different degrees of external damage, which is usually related to lower fillet quality (Borderías and Sánchez-Alonso 2011). Moreover, it is also known that live-captured fish are bled more efficiently and show a lower frequency of rigor mortis onset. Both rigor mortis and bleeding are crucial determinants of the degradation of fish quality (Poli et al. 2005). Additionally, both QIM and IT may have some limitations with respect to detecting small differences in quality since these indices were originally developed to assess storage history and remaining shelf-life (Olafsdóttir et al. 1997; Martinsdóttir et al. 2003). Emerging concerns about fish welfare in commercial fisheries, assessed through pre-slaughter stress levels, will probably contribute to improving both the welfare of fish and final quality of fish products, benefiting both consumers and the fish industry (Metcalfe 2009; Diggles et al. 2011).

Our results suggest that condition factor $(K)$ has some influence on the final quality of the fish. Higher $K$ resulted in poorer quality (i.e. higher $I T$ ) but this was found for gillnetted saithe only, and not for jigged fish (Fig. 3b). It is known that higher $K$ promotes lower perimortem muscle $\mathrm{pH}$ (Einen 1999; Essaiasen et al. 2004) which in turn could lead to reduced fillet quality (Roth and Rotabakk 2012). The higher nutritional levels of fish with higher $K$ would probably account for higher glycogen levels and subsequent lower levels of muscle $\mathrm{pH}$ (Einen 1999). Nonetheless, it seems that this effect arises only in fish struggling for hours in the net and not in jigged fish, which would also prevent the detection of statistical differences in fillet quality related to fishing gear. In this sense, there is a need to account for potential confounding factors, since bentho-demersal saithe (i.e. targeted by gillnets) had higher $K$ and HSI than demerso-pelagic saithe (i.e. targeted by jigging). The latter is in concordance with other studies on gadoids, where $K$ seemed to have some influence on quality drivers such as post-rigor muscle pH (Esaiassen et al. 2004). Thus, both the fishing gear used (i.e. gillnets) and a higher nutritional status of the fish, could have a synergistic influence on final fillet quality. Consequently, more studies resembling 
realistic commercial fishing operations and assessing the quality of the fish, whether dead or not, and accounting for confounding factors such as $K$, are needed to assess the influence of fishing gear on fillet quality of saithe.

\section{Conclusion}

In conclusion, the blood parameters indicated that the stress levels of the fish varied between the fishing methods, and that saithe caught with jigging were less stressed and had better welfare conditions, than fish caught in gillnets. However, our analysis did not detect any quality difference between the two fishing methods. Further studies including dead fish, with larger sample sizes, and using other indicators and their variation over time, are needed to assess the potential influence of fishing gear on fish quality. Knowledge of the factors driving quality of the final product (i.e. fish fillet quality) will be valuable for both consumers and the fish industry.

Acknowledgements. We thank the editor and the two anonymous reviewers for their comments, which significantly improved the manuscript. This study was funded by the Norwegian Seafood Research Fund through the project "Evaluation of actions to promote sustainable coexistence between salmon culture and coastal fisheries, ProCoEx" (Project No. 900772) and the Norwegian Research Council through the strategic project "ECOCOAST: Kyst $\varnothing$ kosystemer i endring". Kilian Toledo-Guedes was supported by a grant from Iceland, Liechtenstein and Norway through the EEA Financial Mechanism. Operated by Universidad Complutense de Madrid.

\section{References}

Akse L., Tobiassen T., Midling K.Ø., Aas K., 2007, Pre-rigor filetering av levendefanget torsk - I Filetkvalitet - vill torsk restituert I merd etter fangst, uten forring. NOFIMA Report 3/2007, 16 p. ISBN: 978-82-7251-5

Anderson M.J., 2001, A new method for non-parametric multivariate analysis of variance. Austral. Ecol. 26, 32-46.

Ashwood E.R., Kost G., Kenny M., 1983, Temperature correction of blood-gas and pH measurements. Clin. Chem. 29, 1877-1885.

Bonilla A.C., Sveindottir K., Martinsdottir E., 2007, Development of Quality Index Method (QIM) scheme for fresh cod (Gadus morhua) fillets and application in shelf life study. Food Control. 18, 352-358.

Borderías A.J., Sánchez-Alonso I., 2011, First processing steps and the quality of wild and farmed fish. J. Food Sci. 76, R1-R5.

Botta J.R., Bonnell G., Squires B.E., 1987, Effect of method of catching and time of season on sensory quality of fresh raw Atlantic cod (Gadus morhua). J. Food Sci. 52, 928-931.

Boutilier R.G., Heming T.A., Iwama G.K., 1984, Appendix: physicochemical parameters for use in fish respiratory physiology. In: Hoar W.S., Randall D.J. (eds.), Fish Physiology X. Academic Press, London, pp. 403-430.

Brown J.A., Watson J., Bourhill A., Wall T., 2008, Evaluation and use of the Lactate Pro, a portable lactate meter, in monitoring the physiological well-being of farmed Atlantic cod (Gadus morhua). Aquaculture 285, 135-140.
Chopin F.S., Arimot T., Inoue Y., 1996, A comparison of the stress response and mortality of sea bream Pagrus major captured by hook and line and trammel net. Fish. Res. 28, 277-289.

Clarke K.R., Gorley R.N., 2006, Primer version 6: user manual/tutorial. PRIMER-E Ltd. Plymouth, 193 p.

Cooke S.J., Suski C.D., Danylchuk S.E., Danylchuk A.J., Donaldson M.R., Pullen C., Bulté G., O’toole A., Murchie K.J., Koppelman J.B., Shultz A.D., Brooks E., Goldberg T.L., 2008, Effects of different capture techniques on the physiological condition of bonefish Albula vulpes evaluated using field diagnostic tools. J. Fish Biol. 73, 1351-1375.

Currey L.M., Heupel M.R., Simpfendorfer C.A., Clark T.D., 2013, Blood lactate loads of redthroat emperor Lethrinus miniatus associated with angling stress and exhaustive exercise. J. Fish Biol. 83, 1401-1406.

Diggles B.K., Cooke S.J., Rose J.D., Sawynok W., 2011, Ecology and welfare of aquatic animals in wild capture fisheries. Rev. Fish Biol. Fisher. 21, 739-765.

Einen O., Mørkøre T., Rørå A.M.B., Thomassen M.S., 1999, Feed ration prior to slaughter - a potential tool for managing product quality of Atlantic salmon (Salmo salar). Aquaculture 178, 149169.

Erikson U., Bye G., Oppedal K., 2009, Fastere filet - industritest og opplæring. Sintef Report SFH80 A095028, 19 p. ISBN: 978-8214-04907-7

Esaiassen M., Nilsen H., Joensen S., Skjerdal T., Carlehög M., Eilertsen G., Gundersen B., Elvevoll E., 2004, Effects of catching methods on quality changes during storage of cod (Gadus morhua) LWT - Food Sci. Technol. 37, 643-648.

Gilmour K.M., Perry S.F., 2009, Carbonic anhydrase and acid-base regulation in fish. J. Exp. Biol. 212, 1647-1661.

Heisler N., 1984, Acid-base regulation in fishes. In: Hoar W.S., Randall D.J. (eds.), Fish Physiology X, London, Academic Press, pp. 315-401.

Hughes D., 1995, Animal welfare: the consumer and the food industry. Brit. Food J. 97, 3-7.

Kestin S.C., van de Vis J.W., Robb D.H., 2002, Protocol for assessing brain function in fish and the effectiveness of methods used to stun and kill them. Vet. Rec. 150, 302-307.

Kieffer J.D., 2000, Limits to exhaustive exercise in fish. Comp. Biochem. Phys. A 126, 161-179.

Lerfall J., Roth B., Skare E.F., Heriksen A., Betten T., DziatkowiakStefaniak M.A., Rotabakk B.T., 2015, Pre-mortem stress and the subsequent effect on flesh quality of pre-rigor filleted Atlantic salmon (Salmo salar L.) during ice storage. Food Chem. 175, $157-165$.

Mandelman J.W., Skomal G.B., 2009, Differential sensitivity to capture stress assessed by blood acid-base status in five carcharhinid sharks. J. Comp. Physiol. B 179, 267-277.

Manire C., Hueter R., Hull E., Spieler R., 2001, Serological changes associated with gill-net capture and restrain in three species of sharks. T. Am. Fish. Soc. 130, 1038-1048.

Martinsdóttir E., Luten J.B., Schelvis-Smit R., Hylding G., 2003, Developments of QIM - past and future. In: Luten J.B., Oehlenschlager J., Olafsdottir G. (eds.), Quality of fish from catch to consumer. Academic Publishers, Wageningen, pp. 265272.

Maruhenda F.C., Toledo-Guedes K., Sanchez-Jerez P., Ibanco-Cañete R., Uglem I., Saether B.-S., 2015, A metabolomics approach to detect effects of salmon farming on wild saithe (Pollachius virens) populations. J. Agric. Food Chem. 63, 10717-10726. 
Metcalfe J.D., 2009, Welfare in wild-capture marine fisheries. J. Fish Biol. 75, 2855-2861.

Nielsen J., Hyldig G., Larsen E., 2002, "Eating quality" of fish - a review. J. Aquat. Food. Prod. T. 11, 125-141.

Norwegian Directorate of Fisheries., 2013, Saithe. www.fisheries.no, Accessed 01/20/2015.

Olafsdóttir G., Martinsdóttir E., Oehlenschläger J., Dalgaard P., Jensen B., Undeland I., Mackie I.M., Henehan G., Nielsen J., Nilsen H., 1997, Methods to evaluate fish freshness in research and industry. Trends Food Sci. Tech. 8, 258-265.

Özyurt G., Özogul Y., Özyurt C.E., Polat A., Özogul F., Gökbulut C., Ersoy B., Küley E., 2007, Determination of the quality parameters of pike perch Sander lucioperca caught by gillnet, longline and harpoon in Turkey. Fisheries Sci. 73, 412-420.

Perry S.F., Gilmour K.M., 2006, Acid-base balance and $\mathrm{CO}_{2}$ excretion in fish: Unanswered questions and emerging models. Respir. Physiol. Neurobiol. 154, 199-215.

Poli B.M., 2009, Farmed fish welfare-suffering assessment and impact on product quality. Ital. J. Anim. Sci. 8, 139-160.

Poli B.M., Parisi G., Scappini F., Zampacavallo G., 2005, Fish welfare and quality as affected by pre-slaughter and slaughter management. Aquacult. Int. 13, 29-49.
Rotabakk B.T., Skipnes D., Akse L., Birkeland S., 2011, Quality assessment of Atlantic cod (Gadus morhua) caught by longlining and trawling at the same time and location. Fish. Res. 112, 4451.

Roth B., Rotabakk B.T., 2012, Stress associated with commercial longlining and recreational fishing of saithe (Pollachius virens) and the subsequent effect on blood gases and chemistry. Fish. Res. 115-116, 110-114.

Santos M.N., Gaspar M.B., Monteiro C.C., Vasconcelos P., 2002, Gill net and long-line catch comparisons in a hake fishery: the case of southern Portugal. Sci. Mar. 66, 433-441.

Wells R.M.G., Pankhurst N.W., 1999, Evaluation of simple instruments for the measurement of blood glucose and lactate, and plasma protein as stress indicators in fish. J. World Aquacult. Soc. 30, 276-284.

Wilkinson R.J., Paton N., Porter M.J.R., 2008, The effects of preharvest stress and harvest method on the stress response, rigor onset, muscle $\mathrm{pH}$ and drip loss in barramundi (Lates calcarifer). Aquaculture 282, 26-32.

Wood C.M., 1991, Acid-base and ion balance, metabolism, and their interactions, after exhaustive exercise in fish. J. Exp. Biol. 160, 285-308. 